\section{Associations of high myopia in childhood}

Abstract

Purpose High myopia in early childhood is a recognised association of ocular and systemic disease. The aim of this study was to describe the types, pattern and frequency of these associations.

Methods All children presenting to two ophthalmology units over 3 years who were found to have high myopia were recruited. High myopia was defined as one or both eyes demonstrating 6 dioptres spherical equivalent or more of myopic refractive error on retinoscopy. We limited the age to less than $\mathbf{1 0}$ years old. A retrospective case review was undertaken of the $\mathbf{1 1 2}$ consecutive children who fulfilled the criteria above. The demographic data, source and indication for referral were recorded along with the ocular and systemic findings and diagnosis. Results Only 9 (8\%) of the children had 'simple high myopia' with no associated ocular or systemic associations. In $54 \%$ there was an underlying systemic association with or without further ocular problems (e.g. developmental delay, prematurity, Marfan,

J.E. Marr

J.R. Ainsworth Birmingham Children's Hospital Birmingham $\mathrm{B} 4$ 6NH, UK

J. Halliwell-Ewen

B. Fisher

L. Soler

J.R. Ainsworth

Department of

Ophthalmology

Birmingham Heartlands

Hospital

Birmingham B9 5S, UK

Dr John Ross Ainsworth, FRCOphth

Eye Department Birmingham Children's Hospital

Steelhouse Lane

Birmingham $\mathrm{B} 46 \mathrm{NH}$, UK e-mail:

j.r.ainsworth@bham.ac.uk

Presented as a poster at the Oxford Ophthalmological Congress, 1998

Received: 20 March 2000 Accepted in revised form: 28 July 2000

preclude associated abnormality: in 4 cases the diagnosis of a systemic condition in the child led to the identification of the disease in at least one myopic relative. Asian $(p<0.001)$ and male $(p<0.05)$ patients were overrepresented in the series.

Conclusion High myopia is strongly associated with systemic and ocular problems; it may be the reason for the child's initial medical referral and an important clue to an underlying systemic or ocular condition. Referrals infrequently originated from community optometrists despite prior attendance. We suggest that all children under 10 years of age with high myopia are referred to a paediatric ophthalmology clinic for review and we propose a structured clinical evaluation in the hospital eye clinic.

Key words Child, Myopia, Ocular associations, Refractive error, Systemic associations
JANE E. MARR,

JUDITH HALLIWELL-EWEN, B. FISHER,

L. SOLER, J.R. AINSWORTH

The refractive power of the eye is largely determined by corneal curvature, power and position of the crystalline lens, and axial length Refractive error in childhood, including the development of myopia, has been reported in the literature over the past 100 years, often with conflicting theories as to aetiology. ${ }^{1,2}$ Myopia is uncommon in the first years of life, ${ }^{3}$ being present in approximately $4-6 \%$ in infants born at full term. ${ }^{4}$ The figure has reduced to $2-3 \%$ in pre-school children ${ }^{5}$ by a hypothesised process of emmetropisation. In 11- to 13-year-olds the incidence has again risen to $4 \%$, and up to $25 \%$ of Caucasian adults will have developed myopia by adulthood. ${ }^{6}$

It is customary to adopt an arbitrary classification into low ( $<6$ dioptres) and high myopia ( $\geqslant 6$ dioptres). Many studies have concentrated on the management of simple myopia in school children; ${ }^{7,8}$ however, earlyonset high myopia may be a more important issue to the child and the hospital eye service. The incidence of high myopia has not been studied previously in childhood.

Whilst the possibility of associated eye and systemic disease is occasionally alluded to,, 10 the pattern and incidence of these associations have not been the subject of previous study. Therefore we set out to undertake a hospitalbased study of high myopia presenting in the first decade of life prior to a funded communitybased project.

\section{Methods}

We conducted a temporally defined retrospective study of all cases of high myopia that presented to Birmingham Heartlands Hospital and Birmingham Children's Hospital during a 3 year period between 1995 and 1998 . A case review was undertaken of the 112 consecutive children who were found to have myopia of 6 dioptres spherical equivalent or more in one or both eyes before the age of 10 years. Demographic data was recorded for the age of the patient at presentation, race, gender, birth history, family history, source and reason for referral. Ophthalmic and medical histories were documented. A full eye examination was performed and in all but one case the children underwent refraction with cycloplegia within 3 months of presentation. Ethnicity was recorded 
Table 1. Source of referral to the hospital eye service

\begin{tabular}{lc}
\hline Referral source & No. (incidence) \\
\hline Primary care & $28(25 \%)$ \\
General practitioner & $11(10 \%)$ \\
Optometrist & $9(8 \%)$ \\
Orthoptic screening & $5(5 \%)$ \\
Health visitor & $3(3 \%)$ \\
School clinic & $11(\%)$ \\
Social worker & $1(1 \%)$ \\
Eye casualty & \\
Hospital specialty & $13(12 \%)$ \\
Paediatrician & $9(8 \%)$ \\
Neonatologist & $6(5 \%)$ \\
Child development clinic & $3(3 \%)$ \\
ENT surgeon & $1(1 \%)$ \\
Haematologist & $11(10 \%)$ \\
Transfer from other unit & \\
Other & $10(9 \%)$ \\
Not identified & $1(1 \%)$ \\
Visual impairment support service &
\end{tabular}

from the hospital information system. The Health Authority provided demographic information from the 1991 census for the population contained within the catchment areas of the two hospitals of the study. ${ }^{11}$

As part of routine investigation, all children with reduced best-corrected visual acuity, nystagmus or symptoms of night or day blindness underwent electrophysiology, according to standard departmental policy.

\section{Results}

\section{Demography}

In the study group the male to female ratio was 66:46, with a statistically signficant male preponderance ( $p<0.05$, chi-squared test with Yates' correction).

The median age at referral was 2.5 years (range 3 days to 9 years 11 months; SD $=2.5$ years). Ninety-eight per cent of subjects fulfilled study criteria at their first refraction and there was no statistical difference between age at referral and age at which 6 dioptres of myopia developed. Fifty-eight per cent of the children were Caucasian, 2\% Chinese, 2\% Afro-Caribbean and 38\% were of Asian origin. The Asian community accounts for $15 \%$ of the population of Birmingham ${ }^{11}$ and the proportion of Asian children in the series was significantly greater than would be expected $(p<0.001$, chi-squared test with Yates' correction).

\section{Referral source}

The children were referred by several professional groups (Table 1) and for a wide variety of reasons. The majority of children in the series were referred to the hospital eye service for a variety of vague or non-specific ocular signs and symptoms. Myopia itself was the indication for referral in only 5 cases. The majority originated from either general practitioners or paediatricians. Few were referred from primary preschool or targeted child development clinic screening.
Only 10 referrals originated from community optometry; in 5 the child was referred because the optician could not improve the visual acuity but myopia was not recognised. In 5 cases high myopia was diagnosed and the child was referred for either cycloplegic refraction (4) or because of poor stereopsis (1). Conversely, in 5 cases the child had previously been seen by a community optometrist and no referral made. In 3 cases a high myopic correction had been prescribed and the child was referred because of concern raised by the health visitor. The refractive error had not been recognised in 1 case and in another child several appointments for review at the optometrist had failed to detect dense amblyopia.

\section{Family history}

A positive family history of ocular abnormality in a firstdegree relative was found in 49 (44\%) of the children with a $29 \%$ prevalence of simple myopia among these family members. A family history of Marfan syndrome, juvenile cataract or high myopia was the reason for referral of 7 children. The elicitation of a family history of Stickler syndrome or nyctalopia was helpful in the diagnosis in 3 cases. More surprisingly, in four families the recognition of Marfan or Stickler syndrome in the child led to the recognition of the disease in other myopic family members.

\section{Refractive error}

One hundred and ten of the 112 children were highly myopic when first refracted: 2 children were initially ineligible but fulfilled study criteria prior to their tenth birthday. Twelve $(11 \%)$ children were highly myopic in one eye only, with the other 100 (89\%) children having bilateral high myopia. The refractive error did not spontaneously decrease in any child. The highest degree of myopia recorded was $-22.00 /+3.00 \times 110$ (in a child with Noonan syndrome) and the highest degree of astigmatism was $-30.00 /+20.00 \times 150$ (in a child with Marfan syndrome and lens subluxation). Thirty-six (32\%) patients demonstrated anisometropia of 2 dioptres or more.

\section{Associations of myopia}

In $9(8 \%)$ children no associated ocular, orthoptic or systemic abnormality was detected during the period of the study, with a minimum 12 month follow-up (Table 2). In 61 (54\%) children there was an underlying systemic association with or without other ocular associations. Of the remaining 42 children, 18 (16\%) had an associated ocular abnormality with or without orthoptic problems and $24(21 \%)$ had high myopia with an orthoptic abnormality (Table 2). 
Table 2. Systemic, orthoptic and ocular abnormalities in children with high myopia

\begin{tabular}{lc}
\hline Abnormality detected & Number (\%) \\
\hline Systemic abnormality alone & $24(22)$ \\
Orthoptic abnormality alone & $24(22)$ \\
Ocular abnormalities alone & $6(6)$ \\
Systemic + orthoptic abnormality & $18(16)$ \\
Ocular + orthoptic abnormality & $12(11)$ \\
Systemic + ocular abnormality & $10(9)$ \\
Systemic + ocular + orthoptic abnormality & $9(8)$ \\
High myopia alone & $9(8)$ \\
Total & $112(100)$ \\
\hline
\end{tabular}

\section{Ocular associations (Table 3)}

In $27(24 \%)$ children there was one or more ocular condition associated with high myopia, with or without a systemic condition or orthoptic abnormality.

\section{Orthoptic associations (Table 3)}

Sixty-three (56\%) children in the series had one or more orthoptic conditions with or without ocular or systemic findings. The incidence of anisometropic amblyopia was $32 \%$. Strabismus was seen in $24(21 \%)$ of the children and $14(12 \%)$ had nystagmus.

Table 3. Ocular abnormalities found in children with high myopia

\begin{tabular}{|c|c|}
\hline Ocular abnormalities detected & $\begin{array}{c}\text { No. (\%) of patients } \\
\text { with ocular } \\
\text { abnormality }\end{array}$ \\
\hline \multicolumn{2}{|l|}{ Refractive } \\
\hline High myopia & $112(100.0 \%)$ \\
\hline Anisometropia > 2 dioptres & $36(32.0 \%)$ \\
\hline \multicolumn{2}{|l|}{ Orthoptic } \\
\hline Anisometropic amblyopia & $36(32.0 \%)$ \\
\hline Strabismus & $20(17.9 \%)$ \\
\hline Nystagmus & $14(12.5 \%)$ \\
\hline \multicolumn{2}{|l|}{ Developmental } \\
\hline Microphthalmos & $1(0.9 \%)$ \\
\hline Aniridia & $1(0.9 \%)$ \\
\hline Spherophakia & $1(0.9 \%)$ \\
\hline Posterior lenticonus & $1(0.9 \%)$ \\
\hline Persistent pupillary membrane & $1(0.9 \%)$ \\
\hline Coloboma & $6(5.4 \%)$ \\
\hline Morning glory disc & $1(0.9 \%)$ \\
\hline \multicolumn{2}{|l|}{ Glaucoma } \\
\hline Glaucoma & $2(1.8 \%)$ \\
\hline Ocular hypertension & $1(0.9 \%)$ \\
\hline \multicolumn{2}{|l|}{ Other lenticular } \\
\hline Cataract & $4(3.6 \%)$ \\
\hline Traumatic lenticonus & $1(0.9 \%)$ \\
\hline Lens subluxation & $5(4.5 \%)$ \\
\hline \multicolumn{2}{|l|}{ Other posterior } \\
\hline $\begin{array}{l}\text { Retinopathy of prematurity stage } 3+ \\
\text { or higher }\end{array}$ & $8(7.1 \%)$ \\
\hline Retinal detachment & $2(1.8 \%)$ \\
\hline \multicolumn{2}{|l|}{ Retinal dystrophies } \\
\hline Cone dystrophy & $3(2.7 \%)$ \\
\hline Congenital stationary night blindness & $3(2.7 \%)$ \\
\hline Ocular albinism & $2(1.8 \%)$ \\
\hline Stargardt disease & $1(0.9 \%)$ \\
\hline
\end{tabular}

Table 4. The incidence of systemic conditions found in children with high myopia

\begin{tabular}{lc}
\hline Systemic condition & No. (\%) \\
\hline Severe developmental delay & $13(11.6 \%)$ \\
Previous extreme prematurity & $11(9.8 \%)$ \\
Stickler syndrome & $10(8.9 \%)$ \\
Down syndrome & $5(4.5 \%)$ \\
Marfan sydnrome & $5(4.5 \%)$ \\
Ehlers-Danlos syndrome & $2(1.8 \%)$ \\
Megalencephaly & $2(1.8 \%)$ \\
Infantile meningitis and subsequent severe & $2(1.8 \%)$ \\
$\quad$ learning difficulties & \\
Gordon syndrome & $1(0.9 \%)$ \\
WAGR syndrome & $1(0.9 \%)$ \\
Noonan syndrome & $1(0.9 \%)$ \\
Smith Magenis syndrome & $1(0.9 \%)$ \\
Congenital toxoplasmosis & $1(0.9 \%)$ \\
Crouzon syndrome & $1(0.9 \%)$ \\
Adams Oliver syndrome & $1(0.9 \%)$ \\
Intrauterine valproate exposure & $1(0.9 \%)$ \\
Oculocutaneous albinism & $1(0.9 \%)$ \\
Hydrocephalus & $1(0.9 \%)$ \\
\hline
\end{tabular}

\section{Systemic association (Table 4)}

The overall incidence of systemic conditions was 53.5\%. The most common associations were of severe developmental delay (11.5\%), previous extreme prematurity $(10 \%)$, Stickler syndrome $(8 \%)$, Down syndrome (5\%) and Marfan syndrome (5\%).

\section{Discussion}

High myopia in early childhood is not included in current recommendations for screening, referral or investigation. ${ }^{12}$ This is despite the fact that high myopia may be the first clue to conditions such as Stickler syndrome, Marfan syndrome or homocystinuria, ${ }^{13}$ and early treatment of certain conditions linked with myopia at an otherwise asymptomatic stage may prolong vision $^{14-17}$ and/or life. ${ }^{13,15-19}$ Even in those conditions where medical treatment is not yet available, accurate and early diagnosis facilitates educational planning, provides the family and care-workers with an understanding of the condition and its consquences, allows accurate genetic counselling during the family's reproductive years, and promotes trust between family and medical team.

As the commonly encountered 'simple' low myopia usually appears later in childhood, we speculated that there may be an age and level at which myopic refractive error is a sufficiently specific indicator of ocular or systemic abnormality to justify referral to the hospital eyd service. To shed light on this issue we investigated the demographics, referral pattern and associations of hight myopia in children.

It was apparent that three categories of abnormality were associated with high myopia, in approximately equal frequency:

- 'Orthoptic' consequences, principally amblyopia or strabismus. 
- Obvious or occult eye disease, such as lens subluxation or retinal dystrophy.

- Obvious or occult systemic disease.

At least one of these three findings was present in the large majority of children, with only $9(8 \%)$ children proving to have 'simple high myopia' following conventional clinical investigation and follow-up.

There was no reliable clue to identify those cases without associated abnormality; neither lack of symptoms or signs, nor normal corrected visual acuity at presentation, nor the presence or absence of a family history of high myopia were reliable indicators of uncomplicated refractive error. Therefore the diagnosis of simple high myopia could only be made by a process of elimination. When reviewing the 112 children in the series we became aware of a need for a systematic approach to clinical examination, as there were many disparate clues to associated ocular and systemic disease. From our experiences we developed a simple clinical approach to the assessment of all children presenting with high myopia in the first 10 years of life. ${ }^{20}$

Whilst high myopia was a valuable clue to underlying disease in many children in the series, in others the associated condition was recognised previously. For instance, correction of high refractive error in the 5 children with Down syndrome in the series was important in visual rehabilitation rather than diagnosis, and our findings emphasise the role of an evidencebased screening protocol for such children, ${ }^{21}$ which is radically different from current practice.

Remarkably few referrals came from the various screening programmes that are designed to identify vision problems in children, such as primary community screening or hospital-based targeted screening. ${ }^{12}$ In addition, both discussion with optometrist colleagues and the study findings indicate that referral for earlyonset high myopia to the hospital eye service by community optometry is not current practice. We suggest that congenital or early-onset high myopia is an uncommon but important finding that requires clinical investigation.

We propose two alterations in practice that might allow early recognition and investigation. A means of refractive assessment, to complement acuity-based orthoptic primary and targeted screening, might be expected to identify virtually all children with high myopia: photorefraction or photoscreening may be able to fulfil such a role. ${ }^{22,23}$ However, with any such suggestion, careful thought and research is required prior to implementation. Secondly, guidelines for referral to the hospital eye service should include children below the age of 10 years with high myopia or high myopic astigmatism.

Usually, conditions requiring intervention or counselling can be detected at a thorough initial assessment in the clinic, and long-term follow-up in the hospital may well not be necessary where only simple axial myopia is found.
Myopia is common, with an incidence ranging from $25 \%{ }^{6}$ up to $70 \%{ }^{24}$ Therefore, it is not surprising that we found a family history of simple myopia in 29 (26\%) children: the rate of myopia in relatives was not greater than would be expected by chance. Ascertaining a family history of known associations of myopia may, however, hasten the diagnosis in the child, particularly in conditions such as retinal dystrophies which may have subtle symptoms and signs. Furthermore the diagnosis of a heritable systemic or ocular association of myopia in the patient may lead to the diagnosis of the same condition in other myopic family members.

Recent discoveries of linkage to chromosomes $18 \mathrm{p}^{25}$ and $12 \mathrm{q}^{26}$ offer hope of better understanding of the small minority of children with truly familial simple high myopia.

The proportion of children of Asian origin in the series was significantly higher than in the catchment areas of the hospitals involved in the study. It may be that high myopia is commoner in this community, and a possible explanation is the increased rate of consanguineous marriage in the Muslim Asian community. ${ }^{27}$ The rate of associations in this group was no different from that in the study population as a whole.

As the study was hospital based, only limited conclusions can be drawn concerning the prevalence and associations of high myopia in the wider paediatric population. As neither the myopia itself not suspicion of associated disease was the indication for referral in the large majority of cases, it would seem that the study group does give some insight into childhood high myopia beyond the hospital setting.

\section{Conclusion}

The high incidence of ocular and orthoptic abnormalities and low incidence of 'simple high myopia' would suggest that all children with high myopia should be referred for an ophthalmological opinion. Although some ocular abnormalities are obvious, other conditions may require directed examination. ${ }^{20}$ In a similar manner, seemingly 'simple' high myopia in the first 10 years of life should prompt consideration of possible associated systemic disease.

\section{References}

1. Curtin BJ. Myopia: a review of its aetiology, pathogenesis and treatment. Surv Ophthalmol 1970;15:1-17.

2. Whitmore WG. The aetiology of myopia. Curr Opin Ophthalmol 1991;2:72-7.

3. Mohindra I, Held R. Refraction in humans from birth to five years. Doc Ophthalmol Proc Ser 1981;28:17-29.

4. Cook RC, Glassock RE. Refractive and ocular findings in the newborn. Am J Ophthalmol 1951;34:1407-13.

5. Laatikainan L, Erkkilä H. Proportion of myopia in visual screening of school children. Doc Ophthalmol Proc Ser 1981;28:1-4.

6. Sperduto RD, et al. Prevalence of myopia in the United States. Arch Ophthalmol 1983;101:405-7.

7. Bedrossian RH. The effect of atropine on myopia. Ophthalmology 1979;86:713-7. 
8. Oakley KH, Young FA. Bifocal control of myopia. Am J Optom Physiol Opt 1975;52:758-64.

9. Whitmore WG. Congenital and development myopia. Eye 1992;6:361-5.

10. Drack AV. Inheritance of refractive errors. In: Traboulsi EI, editor. Genetic diseases of the eye. New York: Oxford University Press, 1998.

11. HM Registrar General. Data from the 1991 Census. Office of Population Censuses and Surveys. London: HMSO, 1995.

12. Joint Working Party of the Royal College of Ophthalmologists and British Paediatric Association. Ophthalmic services for children. London: Royal College of Ophthalmologists, 1994.

13. Cruysberg JRM, Deutman AF. Delay in diagnosis of homocystinuria: retrospective study of consecutive patients. BMJ 1996;313:1037-40.

14. Kaiser-Kupfer MI, Caruso RC, Valle D. Gyrate atrophy of the choroid and retina; long-term reduction of ornithine slows retinal degeneration. Arch Ophthalmol 1991;109:1539-48.

15. Burke JP, O'Keefe M, Bowell R, Naughton ER. A closer look at the eye in homocystinuria: a screened population. J Inerit Metab Dis 1988;11(Suppl 2):237-9.

16. Scott JD. Congenital myopia and retinal detachment. Trans Ophthalmol Soc UK 1980;100:69-71.

17. Tyni T, Kivela T, Lappi $M$, et al. Ophthalmologic findings in long chain 3-hydroxyacyl-CoA dehydrogenase deficiency caused by the G1528C mutation. Ophthalmology 1998;105:810-24.

18. Taylor RH, Burke J, O'Keefe M, Beighl B, Naughton E. Ophthalmic abnormalities in homocystinuria: the value of screening. Eye 1998;12:427-30.
19. Shores J, Berger KR, Murphy EA, Pyeritz RE. Progression of aortic dilatation and the benefit of long-term beta-adrenergic blockade in Marfan's sydnrome. N Engl J Med 1994;330:1335-41.

20. Ainsworth JR, Marr JE. Myopia in young children. Ophthalmic Physiol Opt 2000;20:S1.

21. Warburg M, Risse R. Ophthalmological services to mentally retarded persons: a review and recommendations. Ugeskrift for Laeger 1994;156:6366-9.

22. Simons K. Preschool vision screening: rationale, methodology and outcome. Surv Ophthalmol 1996;41:3-30.

23. Watts P, Walker K, Beck L. Photoscreening for refractive errors in children and young adults with severe learning disabilities using the MTI photoscreener. Eye 1999;13:363-8.

24. Sato T. The causes and prevention of acquired myopia. Tokyo: Kanehara Shuppan, 1957.

25. Young TL, Ronan SM, Drahozal LA, Wildenberg SC, Alvear $\mathrm{AB}$, Oetting WS, et al. Evidence that a locus for familial high myopia maps to chromosome 18p. Am J Hum Genet 1998;63:109-19.

26. Young TL, Ronan SM, Alvear AB, Wildenberg SC, Oetting WS, Atwood LD, et al. A second locus for familial high myopia maps to chromosome 12q. Am J Hum Genet 1998;63:1419-24.

27. Bundey S, Alam H. A five-year prospective study on the health of children in different ethnic groups, with particular reference to the effect of inbreeding. Eur J Hum Genet 1993;1:206-19. 